\title{
Subcutaneous C.E.R.A. for the Treatment of Chronic Renal Anemia in Predialysis Patients
}

\author{
Sedat Üstündağ ${ }^{1}$, Ekrem Doğan², Murat Duranay ${ }^{3}$, Rümeyza Kazancıoğlu ${ }^{4}$, Vedat Çelik ${ }^{5}$, Abdülkadir Ünsal ${ }^{6}$, \\ Lütfullah Altıntepe ${ }^{7}$, Belda Dursun ${ }^{8}$, Ertuğrul Akbaş ${ }^{9}$, Fatih Özdener $^{9}$, Alaattin Yıldız $^{10}$ \\ ${ }^{1}$ Department of Internal Medicine, Division of Nephrology, Trakya University School of Medicine, Edirne, Turkey \\ ${ }^{2}$ Selahaddin Eyyubi University Faculty of Health Sciences, Diyarbakır, Turkey \\ ${ }^{3}$ Clinic of Nephrology, Ankara Training and Research Hospital, Ankara, Turkey \\ ${ }^{4}$ Clinic of Nephrology, Haseki Training and Research Hospital, İstanbul, Turkey \\ ${ }^{5}$ Clinic of Nephrology, Okmeydanı Training and Research Hospital, İstanbul, Turkey \\ ${ }^{6} \mathrm{Clinic}$ of Nephrology, Sişli Etfal Training and Research Hospital, İstanbul, Turkey \\ ${ }^{7}$ Clinic of Nephrology, Konya Training and Research Hospital, Konya, Turkey \\ ${ }^{8}$ Department of Internal Medicine, Division of Nephrology, Pamukkale University School of Medicine, Denizli, Turkey \\ ${ }^{9}$ Roche Pharmaceuticals, İstanbul, Turkey \\ ${ }^{10}$ Department of Internal Medicine, Division of Nephrology, İstanbul University İstanbul School of Medicine, İstanbul, Turkey
}

Background: We investigated the efficacy, safety and tolerability of once-monthly administration of C.E.R.A. in erythropoiesis stimulating agents (ESAs) naive predialysis patients with CKD for anemia treatment

Study Design: Single arm, open label study.

Methods: A total of 75 patients (mean (SD) age was 52.8 (16.4) years, $76.0 \%$ were female) were included in this study conducted between 12 August 2008 and 30 October 2009 in 9 centers across Turkey. The mean change in $\mathrm{Hb}$ concentration $(\mathrm{g} / \mathrm{dL}$ ) between baseline (week 0 ) and the efficacy evaluation period (EEP) was the primary efficacy parameter evaluated in three consecutive periods including a dose titration period (DTP; with initial 1.2 $\mu \mathrm{g} / \mathrm{kg}$ dose of C.E.R.A., subcutaneously, 28 weeks), EEP ( 8 weeks) and a long-term safety period (16 weeks).

Results: Our analysis revealed an improvement in $\mathrm{Hb}$ levels from baseline value of $9.4(0.4) \mathrm{g} / \mathrm{dL}$ to time adjusted average level of $11.4(0.7) \mathrm{g} / \mathrm{dL}$ in EEP in the per protocol (PP) population and from $9.3(0.5) \mathrm{g} / \mathrm{dL}$ to $11.1(1.0) \mathrm{g} / \mathrm{dL}$ in intent-to-treat (ITT) population. Mean (SD) change in Hb levels from baseline to EEP was 2.0 $(0.7) \mathrm{g} / \mathrm{dl}$ in the PP population (primary endpoint) and $1.7(1.1) \mathrm{g} / \mathrm{dL}$ in the ITT population. The percentage of patients whose $\mathrm{Hb}$ concentrations remained within the target range of 10.0-12.0 g/dL throughout the EEP was $43.9 \%$ (95\% CI: $28.5-60.3 \%$ ) in the PP population and $38.7 \%$ (95\% CI: $27.6 \%$ to $50.6 \%$ ) in the ITP population. A total of 206 adverse events (AE) were reported in $77.0 \%$ of patients with hypertension $(20 \%)$ as the most frequent $\mathrm{AE}$.

Conclusion: Once-monthly subcutaneous C.E.R.A. administration is effective and safe in the treatment of anemia in pre-dialysis patients with CKD, who are not currently treated with ESAs.

Keywords: C.E.R.A., chronic kidney disease, efficacy, hemoglobin levels, safety, tolerability
The likelihood of overt anemia increases as the glomerular filtration rate (GFR) declines below $60 \mathrm{~mL} / \mathrm{min}$ in patients with chronic kidney disease (CKD) (1). Exogenous replacement of erythropoietin is now a well-accepted therapy in CKD $(2,3)$ along with growing interest in the use of erythropoiesis stimulating agents (ESAs) (4). Continuous erythropoietin receptor activator (C.E.R.A.; F. Hoffmann-La Roche AG, Turkey) is an ESA developed by attaching a pegylation chain on to epoetin beta, which markedly prolonged the circulating half-life of the molecule to around 130 hours, allowing ad-

Address for Correspondence: Dr. Alaattin Yildız, Department of Internal Medicine, Division of Nephrology, İstanbul University İstanbul School of Medicine, İstanbul, Turkey. Phone: +90 5422427320 e-mail: alayildiz@yahoo.com

Received: 27 January $2015 \quad$ Accepted: 3 June 2015 •DOI: 10.5152/balkanmedj.2016.141173

Available at www.balkanmedicaljournal.org

Üstündağ S, Doğan E, Duranay M, Kazancıoğlu R, Çelik V, Ünsal A, et al. Subcutaneous C.E.R.A. for the Treatment of Chronic Renal Anemia in Predialysis Patients. 
ministration of the drug at extended intervals in the correction as well as maintenance periods $(5,6)$.

Our study was designed to investigate the efficacy, safety and tolerability of monthly administration of C.E.R.A. in predialysis patients with chronic renal anemia (CRA) who are not currently treated with ESAs for the correction and subsequent maintenance of hemoglobin $(\mathrm{Hb})$ concentrations.

\section{MATERIALS AND METHODS}

Seventy-five patients (mean(SD) age: 52.8(16.4) years, $76.0 \%$ females) were included in this single arm, open label study conducted between 12 August 2008 and 30 October 2009 in nine tertiary nephrology centers across Marmara (Edirne, Istanbul), Central Anatolia (Ankara, Konya), Southeastern Anatolia (Diyarbakir) and Aegean (Denizli) Regions of Turkey. Patients aged $\geq 18$ years, diagnosed with CRA, $\mathrm{Hb}$ levels of 8.5-10.0 g/dL, adequate iron status (serum ferritin and transferrin saturation $>100 \mathrm{ng} / \mathrm{mL}$ and $>20 \%$, respectively), no prior ESA therapy for three months prior to enrollment, followed as an outpatient (non-hospitalized) and at pre-dialysis stage (GFR $<30 \mathrm{~mL} / \mathrm{min}$ ) were included. Exclusion criteria are shown in Table 1.

Written informed consent was obtained from each subject and the protocol of the study was conducted in accordance with the ethical principles stated in the "Declaration of Helsinki" and approved by the institutional ethics committee of the coordinator center.

\section{Study visits and data collection}

Eligible patients were enrolled at week 0 . Patients then entered a 28-week dose titration period (DTP). The DTP was followed by an 8-week efficacy evaluation period (EEP) and then a 16-week long-term safety period (LTSP).

\section{Primary efficacy parameter}

The primary efficacy parameter was the mean change in $\mathrm{Hb}$ concentration $(\mathrm{g} / \mathrm{dL}$ ) between baseline (week 0 ) and EEP. The mean $\mathrm{Hb}$ concentration for each individual patient during the EEP was estimated as a time adjusted average $\left(\mathrm{H}_{\mathrm{i}}\right.$ : Hb value at time-point; $\mathrm{t}_{\mathrm{i}}$ : study day; $\mathrm{t}_{0}=$ first day of EEP; $\mathrm{t}_{\mathrm{n}}=$ last day of EEP; $\Sigma$ : Total) by $\hat{\mu}-\frac{1}{2\left(t_{n}-t_{0}\right)} \sum_{i}\left(H_{i}+H_{i-1}\right)\left(t_{i}-t_{i-1}\right)$.

The successive changes in $\mathrm{Hb}$ during all study period were defined by: $\hat{\sigma}=\frac{1}{2\left(t_{n}-t_{0}\right)} \sum\left(H_{i}-H_{i-1}\right)^{2}\left(t_{i}-t_{t-1}\right)$.

\section{Secondary efficacy parameters}

The percentage of patients whose $\mathrm{Hb}$ concentration remained within the target range of 10.0-12.0 $\mathrm{g} / \mathrm{dL}$, the mean
TABLE 1. Exclusion criteria of the study

- Transfusion of red blood cells during the two months prior to enrollment

- Poorly controlled hypertension (systolic/diastolic BP of 170/100 mmHg in the sisstig position despite antihypertensive mediations and requirement for hospitalization in the last 6-months)

- Significant acute or chronic bleeding (e.g. Overt gastrointestinal bleeding)

- Active malignant disease (except non-melanoma skin cancer)

- Hemolysis (based on identification of haptoglobin levels $<30 \mathrm{mg} / \mathrm{dL}$ $(3.54 \mu \mathrm{mol} / \mathrm{L})$ or results of any reliable hemolysis test)

- Hemoglobinopathies (e.g. Homozygous Sickle cell anemia, all types of thalassemia)

- Folic acid deficiency (not corrected within the last 2-month period and based on local laboratory findings such as erythrocyte MCV $105 \mathrm{fl}$ )

- Vitamin B12 deficiency (not corrected within the last 2-month period and based on local laboratory findings such as erythrocyte MCV $105 \mathrm{fl}$ )

- Thrombocyte count $>500 \times 109 / \mathrm{L}$ or $<100 \times 109 / \mathrm{L}$

- Pure red blood cell aplasia

- Epileptic seizure during previous six months

- Congestive heart failure (NYHA Class IV)

- Myocardial infarction or stroke, severe or unstable coronary artery disease, severe liver disease at investigator's discretion, during the previous three months

- Uncontrolled or symptomatic secondary hyperparathyroidism at investigator's discretion

- Pregnancy or lactation period

- Women of child bearing potential with no effective contraceptive method

- Participation in another clinical trial or receiving any study product or treatment in the previous 3 months

- Known hypersensitivity to recombinant human erythropoietin, polyethylene glycol or to any constituent of the study medication,

- Planned (date) elective surgery during the study period except for cataract surgery or vascular access surgery.

time (days) spent in the target range and the time (days) to achievement of response during EEP were amongst the secondary efficacy parameters. Others included the proportion of patients requiring dose adjustments during dose titration and evaluation periods as well as the documentation of RBC transfusions administered during the study in cases of medical need with respect to indications, specified by type, number of units transfused, total volume transfused and pre-transfusion $\mathrm{Hb}$ level.

\section{C.E.R.A. treatment}

C.E.R.A. was administered subcutaneously every four weeks, i.e. weeks $4,8,12,16,20,24,28,32,36,40$, and 44 


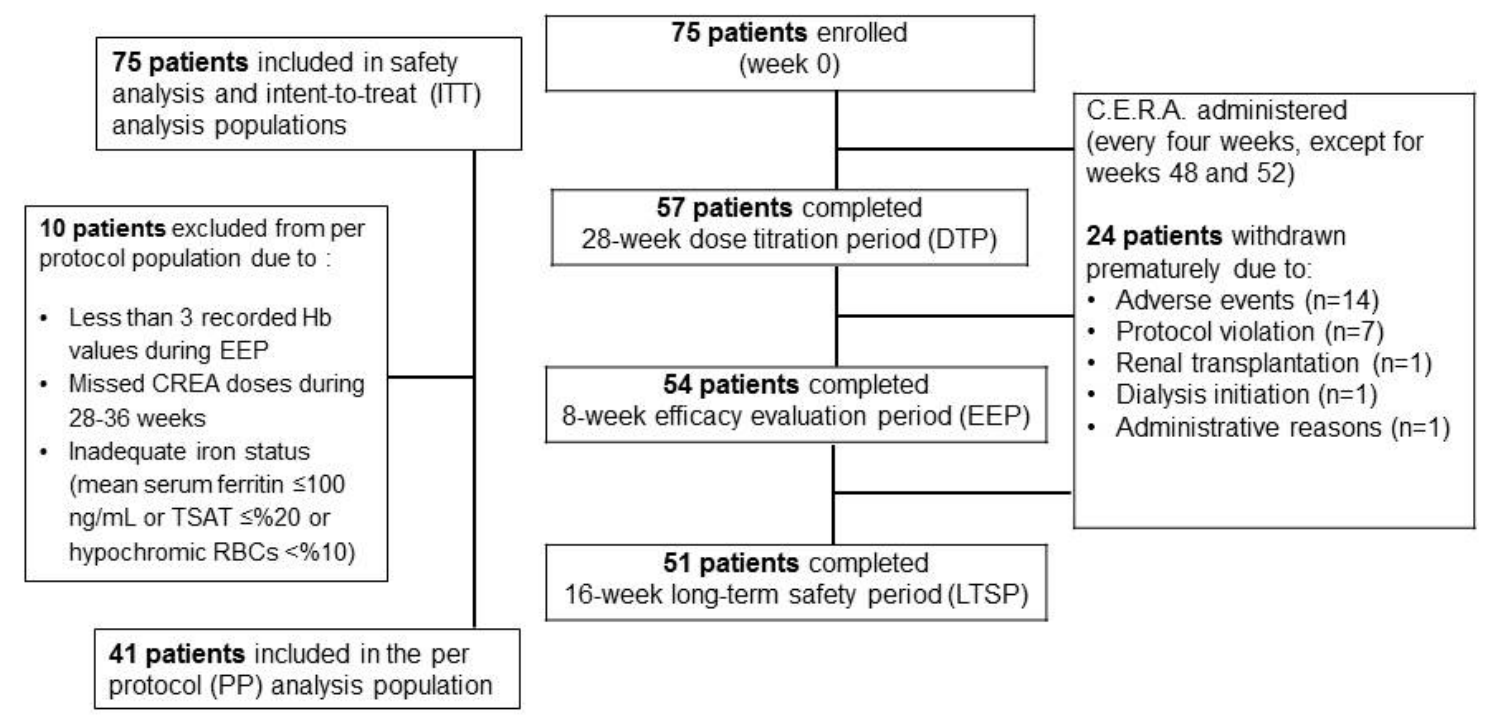

FIG. 1. Patient disposition

but not in weeks 48 and 52, after all visit specific assessments were done.

The initial dose was selected as $1.2 \mu \mathrm{g} / \mathrm{kg}$ subcutaneously every four weeks. Initial dosing and all subsequent adjustments were made using the nearest available Pre-filled Syringe (PFS) or combination of PFSs. Dose adjustment was not performed more frequently than once every four weeks while $\mathrm{Hb}>12 \mathrm{~g} / \mathrm{dL},<10 \mathrm{~g} / \mathrm{dL}$ or $\mathrm{Hb}$ changes of more than $2 \mathrm{~g} / \mathrm{dL}$ per month were avoided.

Once the patient achieved $\mathrm{Hb}$ concentration within the target range, dose adjustments after achievement of response were made to maintain the individual patients' $\mathrm{Hb}$ between 10.0 and $12.0 \mathrm{~g} / \mathrm{dL}$.

\section{Statistical analysis}

All screened patients $(\mathrm{n}=75)$ received at least one C.E.R.A. dose, and were included in safety analysis and intent-to-treat (ITT) analysis populations, while only 41 patients were included in per protocol (PP) analysis population. Data were expressed as "mean \pm standard deviation (SD)", percent (\%) and median (min-max) where appropriate.

Statistical analysis was performed using SPSS computer software (version 13.0, SPSS Inc. Chicago, IL, USA).

\section{RESULTS}

\section{Study population}

Fifty-one patients $(68 \%)$ completed the prescribed course of C.E.R.A. medication. Premature withdrawal $(n=24)$ was due to adverse events in 14 patients, protocol violation in 7 patients, other reasons including renal transplantation $(\mathrm{n}=1)$ and dialysis initiation $(\mathrm{n}=1)$ in two patients and administrative reasons in one patient (Fig 1).

Of the 75 patients who completed a baseline visit, $57 \mathrm{com}-$ pleted the titration period. Fifty-four out of 57 patients completed the evaluation period, and 51 completed the LTSP. While 51 patients completed the LTSP, only 41 were included in the PP analysis population, since 10 patients could not be included in the PP population due to presence of less than 3 recorded $\mathrm{Hb}$ values during the efficacy evaluation period, missed CREA administration during weeks $28-36$ or inadequate iron status (mean serum ferritin $\leq 100 \mathrm{ng} / \mathrm{mL}$ or TSAT $\leq 20 \%$ or hypochromic RBCs $<10 \%$ ) (Figure 1 ).

Demographic data and baseline characteristics related to hemogram and iron parameters are summarized in Table 2.

\section{Primary efficacy parameter}

In the PP population, the mean (SD) $\mathrm{Hb}$ level at baseline was $9.4(0.4) \mathrm{g} / \mathrm{dL}$. The time adjusted average of $\mathrm{Hb}$ during the EEP was $11.4(0.7) \mathrm{g} / \mathrm{dL}$. The mean (SD) change in $\mathrm{Hb}$ concentration between baseline and EEP was $2.0(0.7) \mathrm{g} / \mathrm{dL}$ (Table 3).

Confirming the results in the PP population, in the ITT population, the mean change in $\mathrm{Hb}$ concentration between baseline and EEP was 1.7 (1.1) g/dL with $\mathrm{Hb}$ at baseline of 9.3 $(0.5) \mathrm{g} / \mathrm{dL}$ and the time adjusted average of $\mathrm{Hb}$ during the EEP of $11.1(1.0) \mathrm{g} / \mathrm{dL}$ (Table 3).

Mean $\mathrm{Hb}$ levels in safety population throughout the study are presented in Figure 2. 
TABLE 2. Patient demographics, baseline etiological and clinical characteristics in the safety population $(\mathrm{n}=75)$

\begin{tabular}{|c|c|}
\hline & Mean (SD) \\
\hline Age (years) & $52.8(16.4)$ \\
\hline Gender & $\mathrm{n}(\%)$ \\
\hline Female & $57(76.0)$ \\
\hline Male & $18(24.0)$ \\
\hline Baseline hematologic findings & Mean (SD) \\
\hline $\mathrm{Hb}(\mathrm{g} / \mathrm{dL})$ & $9.3(0.5)$ \\
\hline Erythrocyte MCV (fL) & $88.0(7.6)$ \\
\hline Hct (fraction) & $0.28(0.0)$ \\
\hline Ferritin concentration $(\mu \mathrm{g} / \mathrm{L})$ & $281.6(163.1)$ \\
\hline Transferrin saturation (\%) & $37.2(42.2)$ \\
\hline Iron concentration $(\mu \mathrm{mol} / \mathrm{L})$ & $14.4(10.3)$ \\
\hline Total iron-binding capacity $(\mu \mathrm{mol} / \mathrm{L})$ & $44.1(12.6)$ \\
\hline CRP concentration $(\mathrm{mg} / \mathrm{L})$ & $8.8(12.8)$ \\
\hline White blood cell count $(109 / \mathrm{L})$ & $7.3(2.1)$ \\
\hline Thrombocyte count (109/L) & $252.1(82.6)$ \\
\hline Etiology of CKD* & $\mathrm{n}(\%)$ \\
\hline Diabetes mellitus & $27(36.3)$ \\
\hline Hypertension/large vessel disease & $25(33.3)$ \\
\hline Interstitial nephritis/pyelonephritis & $10(13.3)$ \\
\hline Glomerulonephritis & $5(6.7)$ \\
\hline Polycystic kidney disease & $5(6.7)$ \\
\hline Risk factors* & $\mathrm{n}(\%)$ \\
\hline Arterial Hypertension & $61(81.3)$ \\
\hline IDDM & $15(20.0)$ \\
\hline NIDDM & $15(20.0)$ \\
\hline Hyperlipidemia & $15(20.0)$ \\
\hline PTCA & $7(9.3)$ \\
\hline Myocardial infarction & $5(6.7)$ \\
\hline
\end{tabular}

*observed in $\geq 5 \%$ of the patients.

CKD: chronic kidney disease; Hb: hemoglobin; Hct: hematocrit; CRP-C-reactive protein; IDDM: insulin-dependent diabetes mellitus; NIDDM: non-insulin-dependent diabetes mellitus; MCV: mean corpuscular volume; PTCA: percutaneous transluminal coronary angiography

\section{Secondary efficacy parameters}

The percentage of patients whose $\mathrm{Hb}$ concentrations remained within the target range of 10.0-12.0 g/dL throughout the EEP was 43.9 (18 out of 41 patients) with a 95\% Clopper-Pearson confidence interval from $28.5 \%$ to $60.3 \%$. In the ITT population, the result was $38.7 \%$ ( 29 out of 75 patients) with a $95 \%$ ClopperPearson confidence interval from $27.6 \%$ to $50.6 \%$ (Table 3 ).

The percentage of patients whose time adjusted average $\mathrm{Hb}$ remains within the target range of 10.0-12.0 g/dL throughout the EEP was $73.2 \%$ (30 out of 41 patients) with a $95 \%$ Clopper-Pearson confidence interval from $57.1 \%$ to $85.8 \%$. In the ITT population, the result was $54.7 \%$ (41 out of 75 patients) with a $95 \%$ Clopper-Pearson confidence interval from $42.8 \%$ to $66.2 \%$ (Table 3 ).

The mean (SD) time spent in the target range of 10.0-12.0 $\mathrm{g} / \mathrm{dL}$ during the EEP was calculated to be 40.6 (16.3) days in the PP population and 39.8 (18.2) days in the ITT population. During the DTP, the mean time spent in the target ranges in the PP and ITT populations were 131.6 (43.4) and 109.6 (53.2) days, respectively. During the LTSP, the mean time spent in the target range was 61.1 (24.0) days in the PP population and 59.9 (24.4) days in the ITT population (Table 3 ).

The mean (SD) times for achievement of response in the PP and ITT populations were 24.2 (21.0) and 28.4 (26.0) days, respectively (Table 3 ).

\section{Dose adjustments}

The initial drug dose was patient weight x $1.2 \mu \mathrm{g}$. During the DTP, dose adjustment was necessary in 35 out of 41 patients (85.4\%) in the PP population (Table 2). In the ITT population during the DTP, dose adjustment was necessary in 62 patients $(82.7 \%)$ (Table 3).

All 41 patients in the PP population entered the EEP. The drug dose needed to be adjusted in 23 patients (56.1\%). Fiftyseven patients out of 75 patients included in the ITT population entered the EEP. The drug dose had to be adjusted in 28 patients (49.1\%) (Table 3). In the PP population, all 41 patients entered the LTSP. The drug dose needed to be adjusted in 24 patients $(59 \%)$ (Table 3$)$.

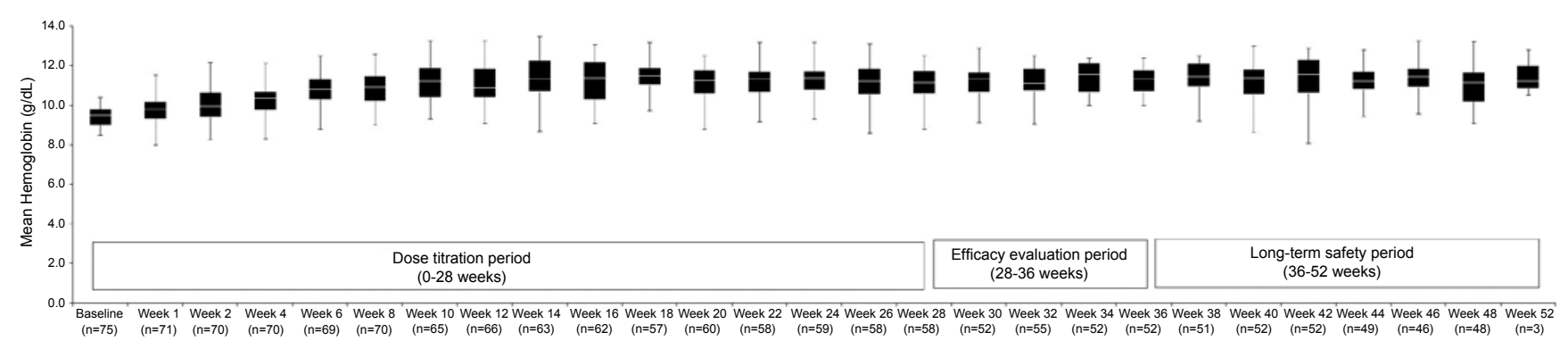

FIG. 2. Hemoglobin levels in the safety population $(n=75)$ 
TABLE 3. Efficacy parameters

\begin{tabular}{|c|c|c|c|c|}
\hline \multirow[b]{2}{*}{ Primary efficacy parameters } & \multicolumn{2}{|c|}{ PP population $(n=41)$} & \multicolumn{2}{|c|}{ ITT population $(\mathrm{n}=75)$} \\
\hline & \multicolumn{2}{|c|}{ Mean (SD) } & \multicolumn{2}{|c|}{ Mean (SD) } \\
\hline $\mathrm{Hb}$ level at baseline $(\mathrm{g} / \mathrm{dL})$ & \multicolumn{2}{|c|}{$9.4(0.4)$} & \multicolumn{2}{|c|}{$9.3(0.52)$} \\
\hline Time adjusted $\mathrm{Hb}$ level during EEP $(\mathrm{g} / \mathrm{dL})$ & \multicolumn{2}{|c|}{$11.4(0.7)$} & \multicolumn{2}{|c|}{$11.1(1.0)$} \\
\hline Change in $\mathrm{Hb}$ (baseline to $\mathrm{EEP})(\mathrm{g} / \mathrm{dL}$ ) & \multicolumn{2}{|c|}{$2.0(0.7)$} & \multicolumn{2}{|c|}{$1.7(1.1)$} \\
\hline Secondary efficacy parameters & $\mathrm{n}(\%)$ & $\mathrm{CI}(\min ; \max )$ & $\mathrm{n}(\%)$ & $\mathrm{CI}(\min ; \max )$ \\
\hline$\%$ with $\mathrm{Hb}$ in the target range* & $18(43.9)$ & $28.5 ; 60.3$ & $29(38.7)$ & $27.6 ; 50.6$ \\
\hline$\%$ with time adjusted $\mathrm{Hb}$ in $\mathrm{TR}^{*}$ & $30(73.2)$ & $57.1 ; 85.8$ & $41(54.7)$ & $42.8 ; 66.2$ \\
\hline Time spent in $\mathrm{Hb} \mathrm{TR}^{*}$ (days) & \multicolumn{2}{|c|}{ Mean (SD) } & \multicolumn{2}{|c|}{ Mean (SD) } \\
\hline During DTP & \multicolumn{2}{|c|}{$131.6(43.4)$} & \multicolumn{2}{|c|}{$109.6(53.5)$} \\
\hline During EEP & \multicolumn{2}{|c|}{$40.6(16.3)$} & \multicolumn{2}{|c|}{$39.8(18.2)$} \\
\hline During LTSP & \multicolumn{2}{|c|}{$61.1(24.0)$} & \multicolumn{2}{|c|}{$59.9(24.4)$} \\
\hline Time to response during EEP (days) & \multicolumn{2}{|c|}{$24.2(21.0)$} & \multicolumn{2}{|c|}{$28.4(26.0)$} \\
\hline Need for dose adjustments & \multicolumn{2}{|c|}{ n (\%) } & \multicolumn{2}{|c|}{ n (\%) } \\
\hline During DTP & \multicolumn{2}{|c|}{$35(85.4)$} & \multicolumn{2}{|c|}{$62(82.7)$} \\
\hline During EEP & \multicolumn{2}{|c|}{$23(56.1)$} & \multicolumn{2}{|c|}{$28(49.1)(\mathrm{n}=57)$} \\
\hline During LTSP & \multicolumn{2}{|c|}{$24(59.0)$} & \multicolumn{2}{|c|}{$29(54.0)(\mathrm{n}=54)$} \\
\hline Change in $\mathrm{Hb}$ concentration $(\mathrm{g} / \mathrm{dL})$ & \multicolumn{2}{|c|}{ Mean (SD) } & \multicolumn{2}{|c|}{ Mean (SD) } \\
\hline Between baseline and DTP & \multicolumn{2}{|c|}{$1.8(0.6)$} & \multicolumn{2}{|c|}{$1.6(0.8)$} \\
\hline Between baseline and LTSP & \multicolumn{2}{|c|}{$1.9(0.8)$} & \multicolumn{2}{|c|}{$1.6(1.2)$} \\
\hline
\end{tabular}

* TR: target range $=10.0-12.0 \mathrm{~g} / \mathrm{dL}$

CI: Clopper-Pearson confidence interval; Hb: hemoglobin; DTP: dose titration period; EEP: efficacy evaluation period; LTSP: long-term safety period

TABLE 4. Extent of exposure to trial medication

\begin{tabular}{llc}
\hline Extent of exposure to trial medication & \multicolumn{2}{c}{ Mean (SD) } \\
\hline Cumulative dose up to week $44(\mu \mathrm{g})$ & \multicolumn{2}{c}{$1016(720.2)$} \\
C.E.R.A monthly dose $(\mu \mathrm{g})$ & Mean $(\mathrm{SD})$ & Median \\
During DTP & $87.8(47.0)$ & 79 \\
During EEP & $82.8(76.3)$ & 68 \\
During LTSP & $78.0(75.1)$ & 60
\end{tabular}

C.E.R.A.: continuous erythropoietin receptor activator; DTP: dose titration period; EEP: efficacy evaluation period; LTSP: long-term safety period

In the ITT population, 54 patients entered the LTSP. The drug dose needed to be adjusted in 29 patients (54\%) (Table 3).

\section{Hb concentration from baseline to DTP or LTSP}

Between baseline and DTP, the mean (SD) changes in $\mathrm{Hb}$ concentration in the PP and ITT populations were $1.8(0.6)$ $\mathrm{g} / \mathrm{dL}$ and $1.6(0.8) \mathrm{g} / \mathrm{dL}$, respectively. Between baseline and LTSP, the mean (SD) change in $\mathrm{Hb}$ concentration was 1.9 $(0.8) \mathrm{g} / \mathrm{dL}$ in the PP population, and $1.6(1.2) \mathrm{g} / \mathrm{dL}$ in the ITT population (Table 3).

\section{Safety results- extent of exposure to trial medication}

The mean (SD) cumulative total dose up to week 44 was $1016(720.2) \mu \mathrm{g}$, and the median was $802.5 \mu \mathrm{g}$. The mean (SD) C.E.R.A. monthly dose was calculated to be 87.8 (47.0) $\mu \mathrm{g}$ during the DTP, 82.8 (76.3) $\mu \mathrm{g}$ during the EEP, and 78.0 (75.1) during the LTSP. The median dose decreased from 79 $\mu \mathrm{g} / \mathrm{mo}$ during DTP, to $68 \mu \mathrm{g} / \mathrm{mo}$ during EEP, and to $60 \mu \mathrm{g} / \mathrm{mo}$ during LTSP (Table 4).

\section{Safety results-adverse events (AEs)}

Seventy-seven percent of the patients reported 206 AEs starting during treatment. The most frequently recorded AEs were hypertension $(20 \%)$ and hyperkalemia $(12 \%)$. A total of 37 drug-related AEs occurred in $21(28.0 \%)$ patients. The most frequently recorded related AEs were hypertension (6.7\% of all patients), blood pressure increased (5.3\%), hyperkalemia (5.3\%), hyperphosphatemia (5.3\%), nausea (2.7\%) and pruritus $(2.7 \%)$. All other related AEs were occurred with a frequency less than or equal to $1.3 \%$ (Table 5).

Thirty serious adverse events were reported in 24 patients. Edema and thrombocytosis were the two serious adverse events considered to be drug-related, while resolved and re- 
TABLE 5. Overview of adverse events in safety population $(n=75)$

\begin{tabular}{|c|c|c|c|}
\hline Safety Analysis Population & $\mathrm{n}$ of AEs & $\mathrm{n}(\%)$ & f patients with AEs \\
\hline AEs (including SAEs) & 206 & & $58(77.3)$ \\
\hline SAEs & 30 & & $24(32.0)$ \\
\hline AEs leading to death & - & & - \\
\hline Drug related AEs & 37 & & $21(28.0)$ \\
\hline AEs leading drug withdrawal & 21 & & $17(22.7)$ \\
\hline AEs with a frequency $>5 \%$ & \multicolumn{3}{|c|}{$\mathrm{n}(\%)$} \\
\hline Hypertension & \multicolumn{3}{|c|}{$15(20.0)$} \\
\hline Hyperkalemia & \multicolumn{3}{|c|}{$9(12.0)$} \\
\hline Constipation & \multicolumn{3}{|c|}{$7(9.3)$} \\
\hline Nausea & \multicolumn{3}{|c|}{$7(9.3)$} \\
\hline Metabolic acidosis & \multicolumn{3}{|c|}{$7(9.3)$} \\
\hline Urinary tract infection & \multicolumn{3}{|c|}{$6(8.0)$} \\
\hline Hyperparathyroidism secondary & \multicolumn{3}{|c|}{$5(6.7)$} \\
\hline Pruritus & \multicolumn{3}{|c|}{$5(6.7)$} \\
\hline Blood pressure increased & \multicolumn{3}{|c|}{$4(5.3)$} \\
\hline Hyperlipidemia & \multicolumn{3}{|c|}{$4(5.3)$} \\
\hline Hyperphosphatemia & \multicolumn{3}{|c|}{$4(5.3)$} \\
\hline Back pain & \multicolumn{3}{|c|}{$4(5.3)$} \\
\hline \multicolumn{4}{|l|}{ AEs leading drug withdrawal } \\
\hline Thrombocytosis & \multicolumn{3}{|c|}{$1(1.3)$} \\
\hline Diabetic retinopathy & \multicolumn{3}{|c|}{$1(1.3)$} \\
\hline Nausea & \multicolumn{3}{|c|}{$1(1.3)$} \\
\hline Chest pain & \multicolumn{3}{|c|}{$1(1.3)$} \\
\hline Pyelonephritis acute & \multicolumn{3}{|c|}{$1(1.3)$} \\
\hline Blood creatine increased & \multicolumn{3}{|c|}{$2(2.7)$} \\
\hline Blood creatinine increased & \multicolumn{3}{|c|}{$1(1.3)$} \\
\hline Creatinine renal clearance decreased & \multicolumn{3}{|c|}{$1(1.3)$} \\
\hline Diabetic foot & \multicolumn{3}{|c|}{$1(1.3)$} \\
\hline Hypervolemia & \multicolumn{3}{|c|}{$1(1.3)$} \\
\hline Metabolic acidosis & \multicolumn{3}{|c|}{$6(8.0)$} \\
\hline Renal failure & \multicolumn{3}{|c|}{$1(1.3)$} \\
\hline Renal failure acute & \multicolumn{3}{|c|}{$1(1.3)$} \\
\hline Dyspnea exertional & \multicolumn{3}{|c|}{$1(1.3)$} \\
\hline Hemodialysis & \multicolumn{3}{|c|}{$1(1.3)$} \\
\hline
\end{tabular}

AE: adverse event; SAE: serious adverse event

covered with sequelae, respectively. Twenty-four serious adverse events started during the DTP, four SAEs occurred during the EEP, and two SAEs started during the LTSP.

Seventeen patients withdrew from the study due to adverse events. A summary of all adverse events leading to treatment withdrawal is provided in Table 5. Twenty-one adverse events in 19 patients led to dose modifications (all screened patients). The most common adverse event leading to dose adjustment was hypertension (11 events).

\section{Safety results- hematology, blood biochemistry, iron parameters and other laboratory findings}

Compared to baseline $\mathrm{Hb}$ values increased by $2 \mathrm{~g} / \mathrm{dL}$ (mean (SD) from $9.3(0.5)$ at baseline to $11.0(0.8) \mathrm{g} / \mathrm{dL}$ at week 48) (Figure 2). For other hematologic laboratory parameters no obvious tendencies in the differences from baseline could be observed during the study. Similarly, no significant changes occurred in blood chemistry and iron parameters during the study (Table 6).

\section{DISCUSSION}

Use of C.E.R.A. at extended intervals has been inherently suitable given its long half-life, slow systemic clearance and low affinity for erythropoietin receptors $(4,7)$. Data from clinical studies (8-13) suggest safe and effective use of C.E.R.A. every 2-4 weeks and once-monthly for correction and maintenance therapy, respectively, in anemic predialysis $(8,10,12$ $17)$ or dialysis $(9,11,18-20)$ CKD patients.

Data from the ARCTOS (Administration of C.E.R.A. in CKD Patients to Treat Anemia with a Twice-Monthly Schedule) study revealed that once every 2 weeks subcutaneous C.E.R.A. was associated with improved $\mathrm{Hb}$ levels and thus amelioration of anemia in ESA-naïve non-dialysis CKD patients, while once-monthly administration maintained stable $\mathrm{Hb}$ levels during the 24-week extension period (12). The CORDATUS study (Correction of Renal Anemia in CKD Patients with Subcutaneous Therapy) also showed efficacy of C.E.R.A. in anemia correction in non-dialysis CKD patients along with a safety profile comparable to darbepoetin alpha (10). Efficacy and safety of C.E.R.A. was also reported in predialysis patients with significant increases in $\mathrm{Hb}$ levels within 6 -12 months of therapy $(13,17)$. Once every 2 week subcutaneous C.E.R.A. in ESA-naïve predialysis CKD patients was reported to be associated with a $2.15 \mathrm{~g} / \mathrm{dL}$ increase in $\mathrm{Hb}$ concentrations within the 28-week follow up along with similar efficacy of the drug within a further 24-week extension period either under every 2 or 4 week regimen (15). Switching of treatment from once weekly darbopoetin alpha to monthly C.E.R.A. was reported to be associated with an increase in the rate for success in correction of anemia in a year from $75.7 \%$ to $80 \%$ in anemic predialysis patients (16).

Notably, albeit pre-dialysis patients in our cohort were younger (53 years vs. 66-70 years) and composed predomi- 
TABLE 6. Blood biochemistry and iron parameters in the safety population

\begin{tabular}{lcccccc}
\hline & \multicolumn{2}{c}{ Baseline } & & \multicolumn{2}{c}{ Week 48 } & \\
\cline { 2 - 3 } & $\mathrm{N}$ & Mean $(\mathrm{SD})$ & & $\mathrm{N}$ & Mean $(\mathrm{SD})$ & $\mathrm{p}$ \\
\hline Albumin $(\mathrm{g} / \mathrm{L})$ & 75 & $37.7(5.7)$ & & 46 & $37.8(4.1)$ & 0.9177 \\
C reactive protein $(\mathrm{mg} / \mathrm{L})$ & 70 & $8.8(12.8)$ & & 40 & $7.8(8.7)$ & 0.6615 \\
Creatinine $(\mu \mathrm{mol} / \mathrm{L})$ & 75 & $289.6(104.1)$ & & 47 & $323.8(133.4)^{*}$ & 0.1163 \\
Phosphate $(\mathrm{mmol} / \mathrm{L})$ & 71 & $1.4(0.3)$ & & 45 & $1.5(0.3)$ & 0.0829 \\
Potassium $(\mathrm{mmol} / \mathrm{L})$ & 75 & $4.9(0.6)$ & & 47 & $4.9(0.7)$ & 1.0000 \\
Ferritin $(\mu \mathrm{g} / \mathrm{L})$ & 73 & $281.6(163.2)$ & & 43 & $238.9(136.6)$ & 0.1518 \\
Iron $(\mu \mathrm{mol} / \mathrm{L})$ & 75 & $14.4(10.3)$ & & 46 & $14.8(5.7)$ & 0.8096 \\
TIBC $(\mu \mathrm{mol} / \mathrm{L})$ & 75 & $44.1(12.6)$ & & 46 & $44.7(12.8)$ & 0.8009 \\
TSAT $(\%)$ & 75 & $37.2(42.2)$ & & 46 & $35.4(17.7)$ & 0.7842 \\
\hline
\end{tabular}

*last measurement was at week 36 according to the protocol

TIBC: total iron-binding capacity; TSAT: transferrin saturation, SD: standard deviation

nantly of females compared with past studies in pre-dialysis patients (15-17), our findings revealed the similar efficacy of once-monthly subcutaneous C.E.R.A. in the correction and maintenance of $\mathrm{Hb}$ levels in pre-dialysis ESA-naïve patients. This seems to indicate the efficacy of C.E.R.A among predialysis anemic patients to be independent of patient demographics including age and gender.

Data from two observational studies indicate the efficacy of C.E.R.A. in treatment of CRA among predialysis CKD patients in real life clinical practice with an increase in $\mathrm{Hb}$ levels from $10.7 \pm 1.4 \mathrm{~g} / \mathrm{dL}$ to $11.5 \pm 1.2 \mathrm{~g} / \mathrm{dL}(21)$ and an overall increase of $1 \mathrm{~g} / \mathrm{dL}$ (22) in ESA-naïve patients during 12-month and 9 months of follow up, respectively.

In fact, 6-month C.E.R.A. treatment was reported to achieve a more marked increase in hemoglobin levels in kidney transplant recipients compared with short-acting ESA (14). Therefore, C.E.R.A treatment seems to be effective in all cases of CRA, regardless of the stage of the disease $(17,21,22)$ or modality selected for renal replacement therapy $(9,11,14,18-20)$.

In our study population, $\mathrm{Hb}$ levels improved from the baseline level of $9.4(0.4) \mathrm{g} / \mathrm{dL}$ to the time-adjusted average level of $11.4(0.7) \mathrm{g} / \mathrm{dL}$ in the PP population, while from $9.3(0.5)$ $\mathrm{g} / \mathrm{dL}$ to $11.1(1.0) \mathrm{g} / \mathrm{dL}$ in the ITT population, with a similar change from baseline to EEP of $2.0(0.7) \mathrm{g} / \mathrm{dL}$ and $1.7(1.1) \mathrm{g} /$ dL, respectively.

Hemoglobin target has been recommended as $11-12 \mathrm{~g} / \mathrm{dL}$ by 2012 National Kidney Foundation Disease Outcomes Quality Initiative (NKF-KDOQI) guidelines (23), while it is 10-12 g/ dL according to the European Medicine Agency (EMA) (24). Notably, time-adjusted average $\mathrm{Hb}$ was maintained within the target range of $10.0-12.0 \mathrm{~g} / \mathrm{dL}$ in $73.2 \%$ of our patients in the PP population ( $95 \% \mathrm{Cl} 57.1-85.8 \%$ ), while only $54.7 \%$ of patients $(95 \% \mathrm{Cl} 42.8-66.2 \%)$ in the ITT population. This lower result in the ITT population can be explained by the possibility of missing a study drug administration for patients in the ITT population, whereas patients in the PP population were not permitted to miss a study drug administration. This seems notable given the suggested potential of achieving stable $\mathrm{Hb}$ concentrations in terms of increased health benefits to patients as well as reduction in the frequency of healthcare interventions (4).

Monthly C.E.R.A therapy was also shown to achieve $\mathrm{Hb}$ levels of $10-12 \mathrm{~g} / \mathrm{dL}$ in the evaluation period in $50 \%$ of predialysis patients with CRA (17). Given the lower likelihood of increasing $\mathrm{Hb}$ levels beyond the recommended targets $(>13 \mathrm{~g} / \mathrm{dL})$ in pre-dialysis patients within the first 8-weeks of C.E.R.A (12.4\%) than darbepoetin alpha (33.5\%) treatment (15), C.E.R.A treatment of anemia seems to retain the range of targeted $\mathrm{Hb}$ levels by offering a more gradual increase in $\mathrm{Hb}$ levels (20) as well as more stabilized Hb levels $(15,17)$.

Given the percent of patients who needed dose changes during EEP (56.1\% in PP and $49.1 \%$ in ITT population) and LTSP $(59.0 \%$ in PP and $54.0 \%$ in ITT population) in the present study, our findings seem consistent with data on the maintenance of stable target $\mathrm{Hb}$ levels (11-12 g/dL) under C.E.R.A. within a 12-month extension period with no need for dose adjustments in nearly $30 \%$ of patients (4).

In this regard, our findings related to requirement of dose adjustment during the DTP in $85.4 \%$ and $82.7 \%$ of patients in the PP and ITT populations, respectively with the need for an increase as well as a decrease in dose during the titration period in $46.3 \%$ and $49.3 \%$ of patients, respectively, emphasize the role of careful titration of the drug dose for adequate treatment.

Increased risk for hypertension, thrombosis and cardiovascular events has been considered amongst the potential nonerythropoietic effects of C.E.R.A therapy in CKD patients (25-27). In this regard, the lack of abnormalities in other laboratory parameters investigated in our patients during the course of C.E.R.A. therapy seems to indicate the target $\mathrm{Hb}$ concentration used in our study population to be appropriate in terms of risk/benefit assessment (28).

In a past meta-analysis in anemic CKD patients treated with recombinant human erythropoietin, a higher $\mathrm{Hb}$ target of $12-16 \mathrm{~g} / \mathrm{dL}$ was reported to be associated with increased risk of all-cause mortality, arterio-venous access thrombosis and poorly controlled hypertension (28). Hence, it is worth noting that hypertension was the most frequently encountered adverse event in our population.

In general, C.E.R.A. was documented to be well tolerated, with no association of the pattern of AEs with the dosage or schedule of regimen (4). In a recent meta-analysis of phase II-III data on C.E.R.A treatment, C.E.R.A was determined to 
be associated with significantly lower rates of AEs and SAEs as compared with other ESAs (29). Likewise, our study confirmed the good safety and tolerability profile of C.E.R.A with the mean cumulative total dose up to week 44 of 1016 (720.2) $\mu \mathrm{g}$ and there were 206 adverse events in $58(77.3 \%)$ patients overall. Thirty SAEs were recorded in $24(32.0 \%)$ patients, two of which were identified to be drug-related. Notably, metabolism and nutrition disorders (10.7\%), metabolic acidosis in particular (8.0\%), were the adverse events most commonly associated with treatment withdrawal. The occurrence of gradual rather than abrupt increase in $\mathrm{Hb}$ levels and stabilization in the follow up seems to have a role in the good safety profile offered by C.E.R.A.

Management of anemia has been considered challenging, involving the frequent administration of conventional ESAs along with the need for $\mathrm{Hb}$ monitoring and dose adjustments $(4,26,27)$. Given the complexity of clinical management of dialysis patients, the introduction of extended administration intervals and less frequent dose changes has been considered to offer a simplified and less time-consuming care and thus to allow the fair distribution of healthcare resources along with a reduction in healthcare costs $(4,30)$.

Certain limitations to this study should be considered. Firstly, the lack of a placebo or comparison group consistent with a single-arm open-label design of the study seems to be the major limitation. The inclusion of patients followed by nine different centers located in diverse geographical regions of our country and high statistical power $(100 \%)$ in the posthoc power analysis increase the ability of our study results to reflect the pre-dialysis patients countrywide, whereas high premature discontinuation rates and predominance of female patients in our cohort limits the extension of the knowledge achieved in the current study other and racial differences should also be considered while interpreting our results for other populations. Secondly, one must remain prudent when interpreting our findings on the safety and tolerability profile, given the inclusion of a very homogeneous patient population with GFR $<30 \mathrm{~mL} / \mathrm{min}$ and the relatively small sample size. Nevertheless, limiting the likelihood of the introduction of selection bias for more responsive or unresponsive patients, patients with CRA were treatment-naïve in terms of RRT and ESA treatment prior to C.E.R.A. and our findings provide data on the effect of C.E.R.A. in a very homogeneous population (only patients with GFR $<30 \mathrm{~mL} / \mathrm{min}$ ) of patients with predialytic $\mathrm{CKD}$, and thus represent a valuable contribution to the available literature.

In conclusion, our findings demonstrate that the use of oncemonthly subcutaneous C.E.R.A. is effective in the correction and maintenance of $\mathrm{Hb}$ levels in pre-dialysis CRA patients.
Ethics Committee Approval: Ethics committee approval was recieved for this study from the ethics committee of İstanbul University İstanbul School of Medicine.

Informed Consent: Written informed consent was obtained from patients who participated in this study.

Peer-review: Externally peer-reviewed.

Author contributions: Concept - A.Y., S.Ü., F.Ö.; Design - A.Y., S.Ü., E.D., M.D., R.K., V.Ç., A.U., L.A., B.D., E.A., F.Ö.; Supervision - A.Y., S.Ü.; Resource - A.Y., S.Ü., F.O.; Materials - A.Y., S.Ü., E.D., M.D., R.K., V.Ç., A.Ü., L.A., B.D., E.A., F.Ö.; Data Collection and/or Processing - A.Y., S.Ü., E.D., M.D., R.K., V.C., A.Ü., L.A., B.D., E.A., F.Ö.; Analysis and/or Interpretation - A.Y., S.Ü., E.D., M.D., R.K., V.Ç., A.Ü., L.A., B.D., E.A., F.Ö.; Literature Search - A.Y., S.Ü., E.D., M.D., R.K., V.Ç., A.Ü., L.A., B.D., E.A., F.O.; Writing - A.Y., S.Ü., E.D., M.D., R.K., V.Ç., A.Ü., L.A., B.D., E.A., F.Ö.; Critical Reviews - A.Y., S.Ü.

Acknowledgements: Authors would like to thank to Prof. Şule Oktay, M.D., PhD and Cağla Ayhan, M.D. from KAPPA Consultancy Training Research Ltd. (İstanbul, Turkey) for their support in manuscript preparation, and to Godehard Hoexter from Dr. M. Koehler GmbH Pharma Biometrie Consulting (Freiburg, Germany) for statistical analysis.

Conflict of Interest: Ertuğrul Akbaş, Murat Duranay and Fatih Özdener are Roche employees. Other authors declare that they have no conflict of interest.

Financial Disclosure: This study is granted by Roche Turkey.

\section{REFERENCES}

1. Astor BC, Muntner P, Levin A, Eustace JA, Coresh J. Association of kidney function with anemia: the third National Health and Nutrition Examination Survey (1988-1994). Arch Intern Med 2002;162:1401-8. [CrossRef]

2. IV. NKF-K/DOQI Clinical practice guidelines for anemia of chronic kidney disease: update 2000. Am J Kidney Dis 2001;37(1 Suppl 1):S182-238. [CrossRef]

3. European best practice guidelines for the management of anaemia in patients with chronic renal failure. Working Party for European Best Practice Guidelines for the Management of Anaemia in Patients with Chronic Renal Failure. Nephrol Dial Transplant 1999;14(Suppl 5):1-50.

4. Besarab A, Salifu MO, Lunde NM, Bansal V, Fishbane S, Dougherty FC, et al; Ba16285 Study Investigators. Efficacy and tolerability of intravenous continuous erythropoietin receptor activator: a 19-week, phase II, multicenter, randomized, open-label, dose-finding study with a 12-month extension phase in patients with chronic renal disease. Clin Ther 2007;29:626-39. [CrossRef] 
5. Macdougall IC. Anaemia and chronic renal failure. Medicine 2011;39:425-9. [CrossRef]

6. C.E.R.A. (Methoxy polyethylene glycol-epoetin beta) Global Summary of Product Characteristics.

7. Macdougall IC, Robson R, Opatrna S, Liogier X, Pannier A, Jordan $\mathrm{P}$, et al. Pharmacokinetics and pharmacodynamics of intravenous and subcutaneous continuous erythropoietin receptor activator (C.E.R.A.) in patients with chronic kidney disease. Clin J Am Soc Nephrol 2006;1:1211-5. [CrossRef]

8. Provenzano R, Besarab A, Macdougall IC, Ellison DH, Maxwell AP, Sulowicz W, et al.; BA 16528 Study Investigators. The continuous erythropoietin receptor activator (C.E.R.A.) corrects anemia at extended administration intervals in patients with chronic kidney disease not on dialysis: results of a phase II study. Clin Nephrol 2007;67:306-17.

9. Locatelli F, Villa G, de Francisco AL, Albertazzi A, Adrogue HJ, Dougherty FC, et al; BA16286 Study Investigators. Effect of a continuous erythropoietin receptor activator (C.E.R.A.) on stable haemoglobin in patients with CKD on dialysis: once monthly administration. Curr Med Res Opin 2007;23:969-79. [CrossRef]

10. Roger SD, Locatelli F, Woitas RP, Laville M, Tobe SW, Provenzano $\mathrm{R}$, et al. C.E.R.A. once every 4 weeks corrects anaemia and maintains haemoglobin in patients with chronic kidney disease not on dialysis. Nephrol Dial Transplant 2011;26:3980-6. [CrossRef]

11. Carrera F, Lok CE, de Francisco A, Locatelli F, Mann JFE, Canaud B, et al; PATRONUS Investigators. Maintenance treatment of renal anaemia in haemodialysis patients with methoxy polyethylene glycol-epoetin beta versus darbepoetin alfa administered monthly: a randomized comparative trial. Nephrol Dial Transplant 2010;25:4009-17. [CrossRef]

12. Kessler M, Martínez-Castelao A, Siamopoulos KC, Villa G, Spinowitz B, Dougherty FC, et al. C.E.R.A. once every 4 weeks in patients with chronic kidney disease not on dialysis: The ARCTOS extension study. Hemodial Int 2010;14:233-9. [CrossRef]

13. Bubic I, Prkacin I, Racki S. [Efficacy and safety of CERA in anemia correction in predialysis patients--Croatian experience]. Acta Med Croatica 2012;66(Suppl 2):42-6.

14. Esposito C, Abelli M, Sileno G, Migotto C, Torreggiani M, Serpieri N, et al. Effects of continuous erythropoietin receptor activator (CERA) in kidney transplant recipients. Transplant Proc 2012;44:1916-7. [CrossRef]

15. Macdougall IC, Walker R, Provenzano R, de Alvaro F, Locay HR, Nader PC, et al. C.E.R.A. corrects anemia in patients with chronic kidney disease not on dialysis: results of a randomized clinical trial. Clin J Am Soc Nephrol 2008;3:337-47. [CrossRef]

16. Minutolo R, Zamboli P, Chiodini P, Mascia S, Vitiello S, Stanzione $\mathrm{G}$, et al. Conversion of darbepoetin to low doses of CERA maintains hemoglobin levels in non-dialysis chronic kidney disease patients. Blood Purif 2010;30:186-94. [CrossRef]

17. Koch M, Henrich D, Faust J, Nawka J, Rath T, Wanner C. Initial use of once-monthly administration of C.E.R.A. is effective and safe in correcting renal anemia in non-dialysis patients: the MERCUR trial. Clin Nephrol 2012;78:189-97. [CrossRef]

18. Levin NW, Fishbane S, Ca-edo FV, Zeig S, Nassar GM, Moran $\mathrm{JE}$, et al. Intravenous methoxy polyethylene glycol-epoetin beta for haemoglobin control in patients with chronic kidney disease who are on dialysis: a randomised non-inferiority trial (MAXIMA). Lancet 2007;370:1415-21. [CrossRef]

19. Sulowicz W, Locatelli F, Ryckelynck JP, Balla J, Csiky B, Harris $\mathrm{K}$, et al. Once-monthly subcutaneous C.E.R.A. maintains stable hemoglobin control in patients with chronic kidney disease on dialysis and converted directly from epoetin one to three times weekly. Clin J Am Soc Nephrol 2007;2:637-46. [CrossRef]

20. Duman N, Uyanik A, Unsal A, Sezer S, Camsari T, Cirit M, et al. Once-monthly continuous erythropoietin receptor activator (CERA) for haemoglobin maintenance in haemodialysis patients with chronic renal anaemia. Clin Kidney J 2014;7:464-9. [CrossRef]

21. Frimat L, Mariat C, Landais P, Koné S, Commenges B, Choukroun $\mathrm{G}$. Anaemia management with C.E.R.A. in routine clinical practice: OCEANE (Cohorte Mircera patients non-dialyses), a national, multicenter, longitudinal, observational prospective study, in patients with chronic kidney disease not on dialysis. BMJ Open 2013;3. pii: e001888. [CrossRef]

22. Heidenreich S, Leistikow F, Zinn S, Baumann J, Atzeni A, Bajeski V, et al; SUPRA Study Group. Monthly administration of a continuous erythropoietin receptor activator provides efficient haemoglobin control in non-dialysis patients during routine clinical practice: results from the non-interventional, single-cohort, multicentre, SUPRA study. Clin Drug Investig 2012;32:99-110. [CrossRef]

23. KDOQI. KDOQI clinical practice guideline and clinical practice recommendations for anemia in chronic kidney disease. Kidney International Supplements 2012;2:279-335. Available at:

24. European Medicines Agency (EMEA). Public Statement. Epoetins and the risk of tumour growth rogression and thromboembolic events in cancer patients and cardiovascular risks in patients with chronic kidney disease. 23 October 2007. Doc ref: EMEA/496188/2007.

25. Fliser D, Dellanna F, Koch M, Seufert J, Witzke O, Hauser IA. The Primavera study protocol design: evaluating the effect of continuous erythropoiesis receptor activator (C.E.R.A.) on renal function in non-anemic patients with chronic kidney disease. Contemp Clin Trials 2011;32:786-92. [CrossRef]

26. KDOQI; National Kidney Foundation. KDOQI Clinical Practice Guidelines and Clinical Practice Recommendations for Anemia in Chronic Kidney Disease. Am J Kidney Dis 2006;47(5 Suppl 3):S11-145.

27. Strippoli GF, Navaneethan SD, Craig JC. Haemoglobin and haematocrit targets for the anaemia of chronic kidney disease. Cochrane Database Syst Rev 2006;4:CD003967. [CrossRef]

28. Phrommintikul A, Haas SJ, Elsik M, Krum H. Mortality and target haemoglobin concentrations in anaemic patients with chronic kidney disease treated with erythropoietin: a meta-analysis. Lancet 2007;369:381-8. [CrossRef]

29. Locatelli F, Mann JF, Aldigier JC, Sanz Guajardo D, Schmidt R, Van Vlem B, et al. C.E.R.A. safety profile: a pooled analysis in patients with chronic kidney disease. Clin Nephrol 2010;73:94-103. [CrossRef]

30. Saueressig U, Kwan JT, De Cock E, Sapède C. Healthcare resource utilization for anemia management: current practice with erythropoiesis-stimulating agents and the impact of converting to once-monthly C.E.R.A. Blood Purif 2008;26:537-46. [CrossRef] 